\title{
SERVIÇO SOCIAL E SAÚdE: UM OLHAR PARA A FORMAÇÃo PROFISSIONAL
}

\section{RESUMO}

O presente artigo surge como síntese das reflexões que foram desenvolvidas na pesquisa de iniciação científica intitulada "Serviço Social e Saúde: um olhar para a formação profissional". Nesta, foram realizados estudos bibliográficos, levantamento documental e pesquisa de campo, através dos quais foi possível compreender as determinações que perpassam pela formação do assistente social, especificamente para o trabalho profissional nos serviços de saúde. A pesquisa permitiu particularizar este debate na realidade do curso de Serviço Social da Universidade Federal do Triângulo Mineiro, que historicamente tem se destacado na formação de profissionais em saúde.

PALAVRAS-CHAVE: Serviço Social. Formação Profissional. Política de Saúde.

\section{ABSTRACT}

\footnotetext{
${ }^{1}$ Assistente Social no Instituto Nacional do Seguro Social/ INSS, graduado em Serviço Social pela Universidade Federal do Triângulo Mineiro - UFTM. E-mail: danielbasilio1@ hotmail.com.

${ }^{2}$ Assistente Social. Docente Adjunta na Universidade Federal do Triângulo Mineiro-UFTM campus de Uberaba/MG. Líder do Grupo de Estudos e Pesquisa em Fundamentos, Formação e Exercício Profissional em Serviço Social/GEFEPSS (cadastrado CNPQ). E-mail: lesliane@ hotmail.com
}

Serv. Soc. \& Saúde, Campinas, SP v.16, n. 1 (23), p. 49-80, jan./jun. 2017 E-ISSN 2446-5992 
This article is a summary of reflections that were developed in the scientific initiation research entitled "Social and Health Service: a look at vocational training". In this, bibliographic studies, documentary survey and field research, through which it was possible to understand the determinations that permeate the social worker training specifically for professional work in the health services. The research made it possible to individualize this debate in the reality of Social work course at Universidade Federal do Triângulo Mineiro, which historically has excelled in the training of health professionals.

KEYS WORDS: Social Work. Professional Qualification. Health Policy.

\section{INTRODUÇÃO}

As reflexões que foram desenvolvidas durante a pesquisa ${ }^{3}$ de iniciação científica, intitulada "Serviço Social e Saúde: um olhar para a formação profissional", teve como objeto de investigação as discussões e práticas referentes à política de saúde no processo de formação do ${ }^{4}$ assistente social no curso de Serviço Social da Universidade Federal do Triângulo Mineiro (UFTM).

A pesquisa foi realizada ${ }^{5}$ por meio de levantamento documental e bibliográfico além de pesquisa de campo através de entrevista com estudantes do $8^{\circ}$ período do curso de graduação em Serviço Social da UFTM.

Os dados da pesquisa possibilitaram particularizar o debate da formação profissional na realidade da universidade, partindo de elementos universais, o que nos permitiu conhecer como o curso de Serviço Social da UFTM tem tratado a temática da política de saúde nas atividades de ensino, pesquisa e extensão.

O Serviço Social na contemporaneidade enquanto profissão, inserida na divisão social e técnica do trabalho, de dimensão investigativa e interventiva atua no enfrentamento das diversas expressões da questão social, mediante a proporção global que assumiram os conflitos advindos da relação contraditória entre capital-trabalho, e nessa dinâmica constitui

\footnotetext{
3 Teve aprovação pelo Comitê de Ética da Universidade - UFTM, sendo o número do parecer 43105615.6.0000.5154 em 2014.

${ }^{4}$ Ao utilizarmos a terminologia no sentido masculino neste artigo, inclusive as vezes escrito a palavra homem não estamos concebendo-a de forma machista e singular no âmbito da discussão de gênero, mas assim, como Paulo Netto e Braz (2006), estamos entendendo-o como parte do gênero humano. Por isso também, não utilizaremos no corpo do texto desta tese gênero o/a, mas entendo-o como gênero humano necessariamente.

${ }^{5}$ Nos anos de 2014 e 2015.

Serv. Soc. \& Saúde, Campinas, SP v.16, n. 1 (23), p. 49-80, jan./jun. 2017 E-ISSN 2446-5992
} 
também uma profissão da área da saúde, mas cujo projeto de formação profissional defendido pela categoria preconiza uma formação generalista.

Dentre as diversas complexidades da realidade social que imbricam a formação e o trabalho profissional do assistente social, e considerando as diversas áreas de atuação, priorizamos neste estudo, aquelas relacionadas à Política de Saúde.

O ensino, a pesquisa e a extensão, enquanto elementos indissociáveis e fundamentais no processo de formação profissional devem estar articulados e em consonância com as exigências curriculares apresentadas e defendidas hegemonicamente pelo Serviço Social brasileiro a partir de seu Projeto Ético-Político. Por isso, as temáticas tratadas na formação profissional devem necessariamente articular teoria e realidade, no sentido da práxis.

Uma inserção qualificada nos espaços de trabalho supõe que o profissional apreenda as questões estruturais que produzem e reproduzem as expressões da questão social, e a partir daí construa mediações que possibilite intervenções direcionadas á emancipação da classe trabalhadora ${ }^{6}$, tendo como horizonte uma nova ordem societária.

Essa postura crítico-reflexiva se inicia no processo de formação profissional, a partir de um consistente aporte teórico-metodológico pautado em fundamentos críticos que sustentam uma compreensão da dimensão ético-política da profissão, inserida na complexidade da realidade social.

A conjuntura hodierna, marcada pela ofensiva neoliberal, por retrocessos nos direitos da classe trabalhadora e pelo avanço do neoconservadorismo, desafia a proposta de formação profissional alinhada nas Diretrizes Curriculares elaboradas pela Associação Brasileira de Ensino e Pesquisa em Serviço Social-ABEPSS (1996) e defendida pela categoria.

Assim, para a desenvoltura das reflexões aqui apresentadas, dividimos em dois momentos: no primeiro, apresentamos elementos universais que possibilitam compreender a formação profissional do assistente social na contemporaneidade e as questões que perpassam pela inserção do profissional nos serviços de saúde.

\footnotetext{
${ }^{6} \mathrm{O}$ projeto profissional hegemônico do Serviço Social defende que a prática profissional deva rumar a emancipação humana dos usuários atendidos pelos serviços. Dentro disso, existem os profissionais que defendem que esta emancipação humana passa necessariamente pela superação da ordem societária capitalista e outros que apostam ainda no caráter civilizatório e humanizador do capital. Aqui partimos da premissa que o Estado democrático de direitos e os serviços públicos via políticas sociais contribuem minimamente para a emancipação política dos usuários, quiçá para a emancipação humana.
} 
E, no segundo momento, particularizamos esse debate na realidade do curso de Serviço Social da UFTM, no sentido de socializar os resultados alcançados na pesquisa e urdir a reflexão acerca do princípio generalista da formação profissional.

\section{Elementos para o debate da interlocução da Política de Saúde na formação profissional do assistente social na contemporaneidade}

No Brasil, a ABEPSS protagonizou, numa perspectiva teórico-histórica e éticopolítica, a discussão, construção e avaliação das diretrizes curriculares para a formação profissional em Serviço Social, culminando com a proposta das "Diretrizes Curriculares para o Curso de Serviço Social”, finalizada em 1996 e aprovadas em 2001, que vieram superar os ranços da abordagem conservadora fincada na formação profissional e processualmente questionada na profissão a partir do Movimento de Reconceituação ${ }^{7}$.

As Diretrizes Curriculares propostas pela ABEPSS preconizam então que

A formação profissional deve viabilizar uma capacitação teóricometodológica e ético-política, como requisito fundamental para o exercício de atividades técnico-operativas, com vistas à apreensão crítica dos processos sociais numa perspectiva de totalidade (DIRETRIZES CURRICULARES, 1996).

Nesse sentido, "falar em formação profissional implica acompanhar a dinâmica da sociedade e a trajetória histórica do próprio Serviço Social, procurando entender os condicionamentos que a sociedade impõe sobre a prática profissional" (SILVA, 1995, p.73). O que faz preciso extrapolar os muros da profissão, se atentando para o movimento histórico, crítico e dialético da sociedade, para a luta de classes e as contradições que dela decorrem, para a relação do Estado com a sociedade mediada por políticas sociais, enfim, para as

\footnotetext{
${ }^{7}$ O movimento de Reconceituação do Serviço Social se estendeu da década de 1960 aos anos 1990, culminando com a proposta do projeto ético-político profissional. O projeto de profissão construído trouxe novas perspectivas à profissão, uma vez que rompeu com influências conservadoras (neotomismo, funcionalismoestrutural positivista) e aproximou-se de um posicionamento crítico-reflexivo, propiciado pela dialética marxiana. O projeto ético-político profissional se fundamenta, do ponto de vista normativo, pelo Código de Ética de 1993 que juntamente com a Lei de Regulamentação profissional (lei 8662/93) dão subsídios à ação profissional, bem como pelas Diretrizes Curriculares para o Curso de Serviço Social de 1996, que direcionam numa perspectiva política e crítico-reflexiva a formação profissional na contemporaneidade. Consultar SILVA, Maria Ozanira Silva e. O Serviço Social e o popular: resgate teórico-metodológico do projeto profissional de ruptura. - 6.ed-São Paulo: Cortez, 2009.
}

Serv. Soc. \& Saúde, Campinas, SP v.16, n. 1 (23), p. 49-80, jan./jun. 2017 E-ISSN 2446-5992 
determinações que perpassam pela formação e prática profissional na sociedade capitalista contemporânea.

As diretrizes curriculares são estruturadas em três núcleos de fundamentação, como um conjunto de conhecimentos indissociáveis e constitutivos da formação profissional: o Núcleo de Fundamentos Teórico-Metodológicos da Vida Social, o Núcleo de Fundamentos da Particularidade da Formação Sócio-Histórica da Sociedade Brasileira, e o Núcleo de Fundamentos do Trabalho Profissional.

O Núcleo de Fundamentos Teórico-Metodológicos da Vida Social abarca a compreensão das diversas esferas da vida social e de suas relações, analisando os componentes e as variáveis que decorrem da interação do ser social com o mundo históricocultural na perspectiva do sujeito coletivo. A interação homem-natureza se dá pela objetivação do pensado, através da capacidade teleológica do homem de realizar trabalho.

Nesse processo, a vida social se constrói nas relações mútuas que os homens estabelecem no processo de produção, a partir do trabalho. A organização das relações sociais se dá na reprodução da satisfação das necessidades vitais, na reprodução da vida material. Ao passo que os homens buscam coletivamente estratégias para suprir suas necessidades materiais de vida, na produção, eles estabelecem relações sociais, desenvolvem habilidades intelectivas e manuais, desenvolvem a linguagem e produzem a sua consciência, se transformando mutuamente na medida em que mediam, regulam e controlam a natureza.

Por outro lado, os homens não produzem suas vidas como querem e como manda sua vontade e almeja sua consciência, mas (re)produzem sob condições determinadas. A objetivação do trabalho, e, portanto, a satisfação das necessidades sociais, a objetivação dos homens por meio da cultura, da filosofia, da arte, acontece mediante a relação entre o desejo, a "vontade orientada a um fim" (MARX, 2013) e os meios objetivos de trabalho disponíveis.

Assim, as questões que envolvem a promoção da saúde são determinadas pelas condições objetivas e subjetivas da realidade social, dito de outro modo, significa que a saúde é determinada pelas condições de vida e trabalho, de acesso a bens e serviços e à informação, mas também pelas ações individuais dos sujeitos envolvidos no processo da vida, perante a estrutura sócio-política.

A doença em sua expressão normativa da vida, como fenômeno individual e em sua expressão coletiva, epidemiológica, onde adquire significado no conjunto das representações sociais e nas reivindicações políticas, está

Serv. Soc. \& Saúde, Campinas, SP v.16, n. 1 (23), p. 49-80, jan./jun. 2017 E-ISSN 2446-5992 
estruturada em uma totalidade social. Como forma adaptativa de vida, resultante das relações dos grupos sociais entre si e com a natureza, mediadas pelo processo de trabalho e doença tem uma historicidade das relações sociais - econômicas, políticas e ideológicas - que se realizam nas sociedades concretas (CORDEIRO, 1984 apud MINAYO, 2013, p. 49).

A saúde, enquanto constituinte da práxis humana, deve ser entendida nas suas múltiplas determinações, num conceito ampliado que envolve as condições de vida e trabalho, a alimentação, a moradia, e que, portanto não está isolada das condições materiais e concretas de vida nesta sociedade de lutas de classes.

A estrutura social de um modo de produção determina as configurações do trabalho e das relações sociais que são estabelecidas histórico e socialmente. Netto (2011, p. 34) citando Marx (1979) afirma que: "O moinho movido pelo braço humano nos dá a sociedade com o suserano; o moinho a vapor nos dá a sociedade com o capitalista industrial".

No modo de produção capitalista, a vida se reproduz de acordo com os ditames da classe detentora dos meios de produção, a qual gesta e controla o processo de trabalho da classe trabalhadora na busca por produzir cada vez mais capital gastando o menos possível. O desenvolvimento das forças produtivas, dos meios de comunicação, da ciência e da tecnologia, intensifica a exploração do trabalho e a degradação das condições de vida e saúde no mesmo processo em que se amplia a produção da mais valia. Assim, a ausência de saúde e o processo de adoecimento da classe trabalhadora representam uma latente expressão da barbárie capitalista, uma vez que esse processo se dá na mesma atividade em que se ampliam a riqueza e a qualidade de vida de uma classe, em detrimento da outra.

O projeto ético político do Serviço Social que abrange o projeto de formação profissional aponta a necessidade da compreensão histórico-crítica da realidade social.

Nesta direção, o Núcleo de Fundamentos da Particularidade da Formação SócioHistórica da Sociedade Brasileira diz respeito aos determinantes econômicos, sociais, culturais e políticos que permeiam e estruturam historicamente a formação da sociedade brasileira. É a compreensão do movimento dialético da sociedade e a valorização das conquistas históricas da classe trabalhadora no que se refere aos direitos sociais; a compreensão da economia política que sustenta a sociedade de classes e os interesses do capital na particularidade brasileira; a discussão da relação histórica entre Estado-Sociedade e as políticas econômicas e sociais implementadas respectivamente pelo Estado e Sociedade. Serv. Soc. \& Saúde, Campinas, SP v.16, n. 1 (23), p. 49-80, jan./jun. 2017 E-ISSN 2446-5992 
Para uma inserção qualificada, crítica e propositiva do assistente social no processo de trabalho em saúde (assim como em outras políticas sociais), é preciso que o profissional compreenda a Política de Saúde a partir das contradições e antagonismos político-ideológicos próprio da lógica da sociabilidade burguesa, ou seja, compreenda a dimensão política da política de saúde.

Com base na teoria social de Marx - a qual nos permite uma compreensão das diversas esferas da vida social em suas relações econômicas, políticas sociais e culturais - é possível analisar a Política de Saúde na sua historicidade e nas múltiplas determinações que a constrói e reconstrói no bojo da luta de classes.

A saúde no capitalismo significa a manutenção de condições físicas, mentais e sociais mínimas para a reprodução da força de trabalho, mercadoria necessária para a produção de mais valia, lucro da classe burguesa. Em contrapartida a assistência à saúde é também uma necessidade objetiva para a produção e reprodução da própria vida social. No Estado democrático-burguês, a Política de Saúde, como as demais políticas sociais, inseridas nessa lógica, possui caráter antagônico, atendendo ao mesmo tempo às necessidades da reprodução da vida social, no sentido da prestação de serviços para a manutenção das condições mínimas para a reprodução da força de trabalho e da própria vida. Por essa ótica, a concepção de saúde, enquanto política social está imbricada na própria contradição de interesses, luta de classes, e antagonismo do modo de produção capitalista.

Historicamente a Política de Saúde no Brasil é marcada pela disputa entre dois projetos antagônicos de gestão e assistência à saúde: o projeto da Reforma Sanitária e o projeto Privatista da Saúde.

O projeto de Reforma Sanitária veio firmar um novo modelo de atenção à saúde, pautado na participação social, centralidade do Estado na oferta dos serviços, com acesso universal, integral e pautado na perspectiva de direito social na concepção de cidadania. $\mathrm{O}$ movimento de Reforma Sanitária, endossado pelos movimentos sociais organizados e pelas camadas populares, no fim dos anos 1970, se constituiu ao longo da história da Política de Saúde no Brasil como um importante movimento de luta e resistência na construção de um projeto popular e democrático para a saúde no Brasil.

A Reforma Sanitária tem como uma de suas estratégias o Sistema Único de Saúde (SUS) e foi fruto de lutas e mobilização dos profissionais de saúde, articulados ao movimento popular. Sua preocupação central é assegurar que o Estado atue em função da sociedade, pautando-se na concepção de Estado

Serv. Soc. \& Saúde, Campinas, SP v.16, n. 1 (23), p. 49-80, jan./jun. 2017 E-ISSN 2446-5992 
Democrático e de direito, responsável pelas políticas sociais e, por conseguinte, pela saúde. O controle social por meio de um de seus mecanismos, os conselhos e conferências foi uma das inovações deste projeto (BRAVO, 2007, p. 93).

A Reforma Sanitária, como aponta Bravo (2007) foi extremamente importante frente às articulações dos movimentos sociais e espaços coletivos, bem como para a construção do Sistema Único de Saúde (SUS), para a consolidação dos espaços institucionalizados de participação social no âmbito da saúde (conselhos e conferências). Tal movimento reverberou no artigo 203 da Constituição Federal de 1988, bem como nas leis orgânicas da saúde, nº 8.080/90, que rege sobre a organização do SUS e na Lei $\mathrm{n}^{\circ}$. 8.142/90, que versa sobre o funcionamento da gestão participativa no âmbito do SUS.

O Sistema Único de Saúde brasileiro, a partir de então passa a ser referência para os outros países (pelo menos do ponto de vista legal) por atuar na perspectiva da democratização do acesso à saúde, da universalização das ações, da adoção de um novo modelo assistencial pautado na integralidade e equidade das ações, a democratização das informações e transparência no uso de recursos e ações do governo, a descentralização com controle social democrático e a interdisciplinaridade nas ações (BRASIL, 1990).

No que se referem à integralidade da assistência, os serviços de saúde e a formulação de estratégias de proteção, promoção e prevenção em saúde, se articulam em uma complexa rede de atendimento, que, de acordo com a Lei 8080/90, atendem o usuário de forma integral e continuada, seja nos serviços de Atenção Primária (Unidades Básicas de Saúde/UBS), seja na Atenção Secundária (Unidade de Pronto Atendimento em Saúde/UPA e Unidade Regional de Saúde/URS) ou Terciária (Hospitais).

Entretanto, a partir da década de 1990, com a ofensiva neoliberal, obtêm-se um retrocesso de algumas lutas já travadas e anteriormente ditas como vencidas no âmbito da saúde pela classe trabalhadora. O contexto passa a ser marcado pela tensão entre o público e o privado, disputa esta que não se extinguiu com a garantia da saúde como direito de todos e dever do Estado no texto constitucional. Pelo contrário, trata-se de uma disputa histórica no que tange à Política de Saúde no Brasil, que assume na atualidade novas formas e roupagens.

O aumento da participação das instituições da Sociedade Civil (OS's, OSCIP's e demais instituições do terceiro setor) na gestão da saúde pública em detrimento da figura do Estado na gestão e assistência à saúde da população é entre outros, reflexos dessa tensão na atualidade. Este cenário retoma para o campo da saúde a filantropia, terceirização e Serv. Soc. \& Saúde, Campinas, SP v.16, n. 1 (23), p. 49-80, jan./jun. 2017 E-ISSN 2446-5992 
mercantilização da política de saúde, o que enfraquece o movimento sanitário e a saúde na lógica de "direito de todos e dever do Estado" (BRASIL, 1988).

Por fim, o Núcleo de Fundamentos do Trabalho Profissional, das Diretrizes Curriculares (ABEPSS, 1996), diz respeito à compreensão dos fundamentos históricos da profissão, do seu processo de institucionalização e suas particularidades enquanto profissão inserida na divisão social e técnica do trabalho.

Significa, ainda, reconhecer o produto do trabalho profissional em suas implicações materiais, ídeo-políticas e econômicas. A ação profissional, assim compreendida, exige considerar as condições e relações sociais historicamente estabelecidas, que condicionam o trabalho do assistente social: os organismos empregadores (públicos e privados) e usuários dos serviços prestados; os recursos materiais, humanos e financeiros acionados para a efetivação desse trabalho, e a articulação do assistente social com outros trabalhadores, como partícipe do trabalho coletivo. Compreender as particularidades do Serviço Social como especialização do trabalho coletivo requer a apreensão do conjunto de características que demarcam a institucionalização e desenvolvimento da profissão. Isto é, tanto as determinações sócio-históricas de sua inserção na sociedade brasileira que perfilam o fazer profissional, quanto à herança cultural que vem respaldando as explicações efetivadas pelo Serviço Social sobre as relações sociais, sobre suas práticas, suas sistematizações e seus saberes (DIRETRIZES CURRICULARES, 1996, p. 12).

Nesse sentido, a compreensão das particularidades do trabalho profissional do Serviço Social, como profissão inserida em diversos espaços dentre os quais a saúde, requer uma análise de seus espaços de atuação historicamente demandados.

No que diz respeito ao trabalho na saúde pública, os esforços profissionais têm se direcionado no sentido da efetivação do Sistema Único de Saúde (SUS), da materialização de seus princípios e diretrizes na rede de atenção à saúde, e fortalecimento enquanto política pública garantida pelo Estado que preste gestão e assistência à saúde de modo universal, descentralizado, integral e participativo.

Bravo (2007) afirma que:

A implantação e desenvolvimento do SUS no país vêm requerendo a atuação do assistente social no processo de (re)organização dos serviços, nas ações interdisciplinares e intersetoriais, no controle social, entre outras demandas que expressam a abrangência do conceito de saúde vigente, especialmente nos municípios, que é onde se concretizam as ações e serviços de saúde, buscando fortalecer a perspectiva da universalização do acesso a bens e serviços relativos aos programas e políticas sociais (BRAVO, 2007, p. 50). 
É importante observar, conforme aponta os Parâmetros para Atuação de Assistentes Sociais na Saúde, que as contradições que envolvem a política de saúde vão "impactar o trabalho do assistente social em diversas dimensões: nas condições de trabalho, na formação profissional, nas influências teóricas na ampliação das demandas e na relação com os demais profissionais e movimentos sociais" (CFESS, 2010, p. 21).

O trabalho do assistente social é eminentemente mediatizado pelas contradições que marcam ideologicamente a Política de Saúde, uma vez que seu trabalho não acontece de modo independente, apenas como deseja sua consciência profissional, mas são as instituições empregadoras que circunscrevem o processo de trabalho do profissional, imprimindo também sentido e direção política e ideológica ao seu fazer (IAMAMOTO, 2009).

Assim sendo, "os dois projetos políticos em disputa na área da saúde [o projeto da reforma sanitária e o privatista], passam a apresentar diferentes requisições para o Serviço Social" (BRAVO, 2007).

O projeto privatista vem requisitando ao assistente social, entre outras demandas, a seleção socioeconômica dos usuários, atuação psicossocial por meio do aconselhamento, ação fiscalizatória aos usuários dos planos de saúde, assistencialismo por meio da ideologia do favor e predomínio de práticas individuais. Entretanto, o projeto da reforma sanitária vem apresentando como demandas que o assistente social trabalhe nas seguintes questões: democratização do acesso às unidades e aos serviços de saúde, estratégias de aproximação das unidades de saúde com a realidade, trabalho interdisciplinar, ênfase nas abordagens grupais, acesso democrático às informações e estímulo à participação popular (CFESS, 2010, p. 24).

Como observado, existe uma relação entre as intervenções demandadas pelo projeto sanitarista e os objetivos da profissão a partir do Movimento de Reconceituação Profissional. Tanto o projeto ético-político profissional quanto o projeto da Reforma Sanitária apresentam uma potencialidade civilizatória antagônica à lógica de civilização e sociabilidade do capital.

Ambos os projetos se alicerçam no nexo da justiça social, da defesa dos direitos sociais, da cidadania, do Estado democrático de direito, da saúde como conceito amplo e seus determinantes sociais, prioridade nas ações de promoção e prevenção, e da política de saúde na lógica universal, integral e sob a gestão participativa. Contrapõe-se, portanto à lógica gerencial de mercado sob as políticas sociais, à prevalência das ações curativas e centrada no indivíduo defendido pela lógica privatista (CFESS, 2010) 
Como anteriormente assinalado, são as expressões da questão social advindas das contradições da luta de classes que vão, em grande medida determinar e ocasionar as demandas profissionais do assistente social enquanto profissional inserido na divisão social e técnica do trabalho. Todavia essas contradições não se apresentam no cotidiano profissional em sua concreticidade, esconde a essência e as determinações substanciais dos fenômenos sociais que demandam ações do profissional.

No cotidiano da vida social capitalista as causas das demandas profissionais se apresentam infladas pelo imediatismo aparente da vida cotidiana, mistificadas pelo utilitarismo burguês e produzidos pelas práticas exploradoras dos homens no cotidiano. Nas palavras de Kosik (1969), no cotidiano impera o "mundo da pseudoconcreticidade". Este é justamente a existência autônoma dos produtos do homem e a redução do homem ao nível da práxis utilitária. Neste sentido, é um claro-escuro de verdade e engano. O fenômeno indica a essência e, ao mesmo tempo a esconde. A essência se manifesta no fenômeno, mas só de modo inadequado, parcial ou apenas sob certos ângulos e aspectos (KOSIK, 1969).

De acordo com Netto (2011, p. 6) "toda ciência seria supérflua se a forma de manifestação [a aparência] e a essência das coisas coincidissem imediatamente" (NETTO, 2011, p. 6).

No processo de trabalho no qual se insere, o assistente social necessita de sua capacidade teórico-metodológica, fundamentada pela teoria social crítica, para reproduzir idealmente a essência do objeto que investiga e intervém. Uma inserção qualificada nos espaços de trabalho supõe que o profissional apreenda a essência da vida cotidiana capitalista, pois é nela que se manifestam as expressões da questão social, objeto de intervenção/investigação profissional do assistente social (ABEPSS, 1996). Apreender a cotidianidade em sua essência exige o esforço intelectivo de cooptar a dinâmica e a estrutura sob a qual se produz e reproduz a vida social, uma vez que o cotidiano "é o espaço da produção e reprodução da vida social, construído e constituído na história" (NETTO, 2012, p. $11)$.

Uma teoria social da sociedade burguesa, portanto, tem que possuir como fundamento a análise teórica da produção das condições materiais da vida social. Este ponto de partida não expressa um juízo ou uma preferência pessoal do pesquisador: ele é uma exigência que decorre do próprio objeto de pesquisa - sua estrutura e dinâmica só serão reproduzidas com veracidade no plano ideal a partir desse fundamento; o pesquisador só será fiel ao objeto se atender a tal imperativo (NETTO, 2011, p. 11). 
Nos Parâmetros para Atuação dos Assistentes Sociais na Saúde, o Conselho Federal de Serviço Social (CFESS) aponta algumas questões que envolvem a relação teoria e método no Serviço Social, especificamente da teoria marxista enquanto fundamentação para o trabalho da saúde:

Ao mesmo tempo em que a década de 1990 é marcada pela hegemonia da tendência à intenção de ruptura e, não por acaso, quando o Serviço Social atinge sua maioridade intelectual; é também, nesta mesma década, que se identifica a ofensiva conservadora a esta tendência. O questionamento à tendência a intenção de ruptura afiram que o marxismo não apresenta respostas para o conjunto dos desafios postos à profissão pela contemporaneidade. [...] Na saúde, em que esse embate claramente se expressa, a crítica ao projeto hegemônico da profissão passa pela reatualização do discurso da cisão entre o estudo teórico e a intervenção, pela descrença da possibilidade da existência de políticas públicas, e sobretudo, na suposta necessidade da construção de um saber específico na área, que caminha tanto para a negação da formação original em Serviço Social ou deslancha para um trato exclusivo de estudos na perspectiva da divisão clássica da prática médica (CFESS, 2010, p. 25).

Calcado em Minayo (2013) alinhadamente a discussão do CFESS (2010), temos que a proposta critica-dialética é a que da amplitude no debate profissional e vislumbra a articulação da profissão com as lutas e movimentos mais gerais da classe trabalhadora, num proposito de defesa do projeto de Reforma Sanitária.

Pelo fato de a área de saúde ser um campo que necessariamente junta teoria e prática de forma imediata, a posição marxista em seu viés históricoestrutural, em relação às outras correntes de pensamento (positivismo e fenomenologia) passou a tomar, no Brasil, nos anos 1970 e 1980, o caráter de posição ideológica e política, repercutindo nos movimentos sociais e sendo fertilizada por eles e, ao mesmo tempo, influenciando questões relativas ao direito e outros temas emergentes (MINAYO, 2013, p. 127).

Desta forma, destaca-se a importância que a discussão das categorias ontológicas e reflexivas da teoria de Marx possui na formação e no trabalho profissional dos assistentes sociais, enquanto direção teórico-metodológica de combate às análises e intervenções profissionais focalizadas e paliativas, e ressalta um trabalho profissional crítico-reflexivo, a partir de uma análise de totalidade das expressões da questão social.

Considerando os núcleos que fundamentam a formação profissional crítica do assistente social como um conjunto articulado de conhecimentos, entendemos que para a compreensão do trabalho profissional do assistente social na saúde, não basta o conhecimento Serv. Soc. \& Saúde, Campinas, SP v.16, n. 1 (23), p. 49-80, jan./jun. 2017 E-ISSN 2446-5992 
da política de saúde em si, com suas regulamentações, contradições, possibilidades e desafios, tão pouco basta o conhecimento dos instrumentais técnicos que subsidiam a prática profissional.

É necessário que o profissional assuma uma direção ético-política em seu exercício profissional e que, portanto, tenha uma intencionalidade no seu fazer. Intencionalidade esta que é construída pelo conjunto de conhecimentos do agente profissional (dos fundamentos do trabalho profissional, da política social na qual se trabalha das questões éticas que envolvem a prática profissional) e pelas demandas das instituições e dos usuários. Entendemos assim, que não são apenas as disciplinas estruturadas na matriz curricular da graduação em Serviço Social que abordam diretamente a política de saúde que subsidiam a compreensão da prática profissional em saúde, mas também o conjunto de disciplinas que abordam os fundamentos teórico-metodológicos, ético-políticos e técnico-operativo do trabalho profissional.

\section{A Política de Saúde na formação profisssional em Serviço Social na UFTM}

As reflexões acima, construídas durante o estudo bibliográfico, nos ofereceram os elementos universais para particularizar nossas análises na realidade do curso de Serviço Social da UFTM.

Foi realizado um estudo da temática por aproximações sucessivas, com debates a partir das referencias e revisão de bibliografias que debatem o Serviço Social na saúde e a formação e o trabalho profissional nesse contexto ${ }^{8}$, com destaque para Vasconcelos (2011), Bravo (2007), Mota (2009) e Iamamoto (2012).

$\mathrm{Na}$ exploração de dados da realidade local referentes ao ano de 2014 e primeiro semestre de 2015, foi colhido informações com os docentes do curso e assistentes sociais do Núcleo de Estágio em Serviço Social da UFTM. Também realizamos pesquisa documental nos dois projetos pedagógicos do curso de Serviço Social da UFTM, nas legislações que regulamentam a formação e a prática profissional do assistente social (Diretrizes

\footnotetext{
${ }^{8}$ É importante ressaltar que no levantamento das bibliografias encontramos um artigo científico publicado por docentes e estudantes do curso de Serviço Social acerca da experiência da UFTM na formação de assistentes sociais para o trabalho na saúde. O artigo intitulado "Formação Profissional do Assistente Social na UFTM: a saúde nas atividades de pesquisa e extensão" foi publicado nos Anais do "V Fórum Sócio jurídico: direito à saúde e à dignidade humana" promovido pela Unesp de Franca em 2013 e serviu de base para nossas análises desde a criação do curso até o ano de 2012.
}

Serv. Soc. \& Saúde, Campinas, SP v.16, n. 1 (23), p. 49-80, jan./jun. 2017 E-ISSN 2446-5992 
Curriculares, lei n.8.662 de 1993 e Código de Ética), além dos Parâmetros para Atuação dos Assistentes Sociais na Saúde e as legislações que regulamentam a Política de Saúde no Brasil (Lei orgânica n. 8080 e a Lei n. 8142 ambas de 1990).

A análise desses documentos nos permitiu uma compreensão da totalidade do objeto estudado, nas suas determinações universais, singulares e particulares. Além disso, foi realizada entrevista semiestruturada, com formulário norteador e auxílio de gravador, com 04 estudantes do $8^{\circ}$ período do curso de graduação em Serviço Social da UFTM no ano de 2015/2, no intuito de apreender a realidade vivenciada pelos estudantes no que tange às suas experiências na saúde durante a formação profissional no curso.

A amostragem foi intencional, sendo 02 estudantes que durante sua formação tiveram aproximação com a área da saúde, e outros 02 estudantes que nunca estiveram inseridos nem em estágio, pesquisa e extensão na saúde.

$\mathrm{Na}$ garantia do sigilo da identidade dos sujeitos, preconizada pela resolução n.466/2012 do Conselho Nacional de Saúde, optamos por identificar os sujeitos com 04 nomes de planetas do sistema solar, sendo: Marte, Júpiter, Saturno e Plutão.

Por meio dos processos metodológicos supracitados foi possível alcançar os objetivos da pesquisa. Este movimento se deu através do concreto pensado, no qual buscamos apreender as múltiplas determinações que perpassam pela formação profissional em Serviço Social no campo da saúde especificamente na particularidade da UFTM.

Importante contextualizar que até o ano de 2005, a Universidade de Medicina do Triângulo Mineiro funcionava como uma faculdade e oferecia formação somente na área de saúde, através dos Cursos de Graduação em Medicina, Enfermagem e Biomedicina. Neste ano, ela transforma-se na Universidade Federal do Triangulo Mineiro - UFTM, iniciando um processo de expansão, que se consolida em 2007, com sua adesão ao Programa de Apoio a Planos de Reestruturação e Expansão das Universidades Federais (REUNI), que tem como objetivo a ampliação e expansão da oferta de cursos superiores nas instituições públicas.

O REUNI, dados seus limites estruturais e políticos criou condições para a expansão da rede federal de educação superior, visando o aumento no número de vagas, a criação de cursos no período noturno e o combate à evasão dos docentes. Na UFTM, a adesão ao 
REUNI possibilitou a criação, em 2009, dos cursos de Licenciaturas em Química, Física, Matemática, Ciências Biológicas, História e Geografia e Bacharelado em Serviço Social.

A criação do Curso de Serviço Social coaduna com a luta da categoria por mais cursos em universidade pública, bem como as demandas da região do triângulo mineiro, que possui um alto nível de crescimento econômico e político; também atende o direito da população à educação superior pública. Neste sentido, a criação do curso de Serviço Social na UFTM vem ao encontro às novas demandas para uma formação interdisciplinar e sintetiza

[...] o desafio de decifrar os novos tempos para que deles se possa ser contemporâneo. Exige-se um profissional qualificado, que reforce e amplie a sua competência crítica; não só executivo, mas que pensa, analisa, pesquisa e decifra a realidade. Alimentado por uma atitude investigativa, o exercício profissional cotidiano tem ampliadas as possibilidades de vislumbrar novas alternativas de trabalho nesse momento de profundas alterações na vida em sociedade. O novo perfil que se busca construir é de um profissional afinado com a análise dos processos sociais, tanto em suas dimensões macroscópicas quanto em suas manifestações quotidianas; um profissional criativo e inventivo, capaz de entender o "tempo presente, os homens presentes, a vida presente" e nela atuar, contribuindo, também para moldar os rumos de sua história (IAMAMOTO, 2009, p. 49).

É importante dizer que o projeto político e pedagógico do curso destaca a demanda por profissionais na área da saúde como um dos fatores para a criação do curso na UFTM.

Historicamente na UFTM, as justificativas para implantação do Curso de Serviço Social estão arraigadas na predominância da política de saúde no município e da realidade do Hospital das Clínicas, em que a demanda de mercado para assistentes sociais se faziam presentes (UFTM, 2014, p. 21).

Desde sua implantação, o curso de Serviço Social da UFTM oferece semestralmente 30 vagas, sendo as formas de ingresso realizadas por meio de vestibular, transferência interna, (re)opção de curso, transferência externa, mobilidade estudantil e vagas disponíveis para portador de diploma de nível superior. Atualmente o curso conta com 14 docentes, dos quais $28 \%$ têm a saúde como área de atuação profissional.

De acordo com o projeto pedagógico, o curso de Serviço Social da UFTM tem como perfil do egresso:

[...] o profissional que tem capacidade para fazer a leitura crítica da realidade social, para reconhecer cientificamente as expressões da questão social e identificar os espaços ocupacionais do profissional, apontando as possibilidades de intervenção do assistente social com base na 
fundamentação teórico-metodológica, ético-político e técnico-operativa (UFTM, 2010, p. 56).

Para atingir o objetivo de formar profissionais com esse perfil é necessária uma articulação de unicidade entre as atividades de ensino, pesquisa e extensão.

Cabe destacar que Uberaba/ $\mathrm{MG}^{9}$, local onde a UFTM está situada, se destaca na região do Triângulo Mineiro como um dos principais centros de atendimento médico, hospitalar. A UFTM se insere neste contexto, através de um complexo hospitalar credenciado pelo Sistema Único de Saúde - SUS que oferece atendimento em diversas especialidades, realizando procedimentos de alta complexidade e atendendo pacientes de Uberaba, de diversos municípios de Minas Gerais e também de outros Estados.

Assim, a UFTM tem desenvolvido produção de conhecimentos e prestação de serviços principalmente para área da saúde, a qual se constitui também espaço sócioocupacional para o assistente social, o qual, é reconhecido como profissional de saúde de nível superior, juntamente com outras categorias, pelo Conselho Nacional de Saúde, através da Resolução CNS n. ${ }^{\circ}$ 218, de 6 de março de 1997, conforme indica o projeto pedagógico do curso:

O assistente social como profissional de Saúde tem competência para atuar junto aos fenômenos socioculturais e econômicos que reduzem a eficácia da prestação dos serviços no setor, quer seja em nível de promoção, prestação e/ou recuperação de saúde. O assistente social é, pois, um profissional de saúde que vem colaborar com a posição que emerge da categoria - fruto de avanços obtidos na trajetória histórica da profissão, buscando a garantia da qualidade da prestação de serviços de saúde, numa perspectiva de universalidade e integralidade à população brasileira (Parecer CFESS, 06/06/1990 apud UFTM, 2010, p. 23).

Neste movimento da realidade da UFTM, no processo da pesquisa perguntamos aos estudantes participantes sobre a importância/contribuição do assistente social nos serviços de saúde, pela qual responderam:

É difícil de responder, porque eu nunca participei de estágio na área da saúde. Mas de todos os profissionais da saúde, acredito que o assistente social tem um olhar diferente. Principalmente, por conta da nossa formação. A gente parte para realidade, [...] não fica só no âmbito da doença. [...]. O Serviço Social vai tratar de outras questões, vai ver a realidade desse

\footnotetext{
${ }^{9}$ Em Uberaba/MG situa-se o campus I da UFTM, sendo esta expandida com campus II em Iturama/MG.
} 
paciente, seu cotidiano. Mas eu acho que não é isso que acontece por conta da imediaticidade das tarefas etc (MARTE, 2015).

Eu acredito que numa equipe multiprofissional cada um tem suas atribuições de acordo com a regulamentação da profissão, Código Ética. Então cada profissional [...] dentro das suas atribuições, competências [...]. O assistente pode criar meios de comunicação acerca de direitos voltados para saúde e fortalecer também o SUS a luta por esse direito público (SATURNO, 2015).

Eu acho que o assistente social é muito importante porque ele não vai olhar só pra doença, [...], mas vai analisar o contexto, a realidade que aquele paciente está inserido, vai ver por que as vezes ele está morando em uma área de risco por isso que ele contraiu aquela doença, vai trabalhar todo o aspecto social mesmo dele. Às vezes os médicos passam medicamentos que não são acessíveis, o assistente social vai ter essa intervenção, trabalhar tanto com o médico, vai ter a oportunidade de trabalhar com paciente também como ele pode acessar esse medicamento. E entender esse contexto que o indivíduo está inserido na sociedade que não está deslocado, ele não teve uma doença do nada ele pode ter contraído aquela doença por ta morando em uma área de risco está exposto a alguma coisa no campo de trabalho dele (JUPITER, 2015).

Acredito que o assistente social é importante em vários espaços nessa sociedade capitalista cheia de expressões da questão social e na saúde é mais um espaço que o assistente social tem que estar presente acompanhando a equipe multiprofissional, e de acordo com o seu trabalho cada profissional vai identificando as possibilidades de efetivação dos direitos dos usuários da saúde (PLUTÃO, 2015).

Observa-se que inúmeros são os desafios apresentados cotidianamente ao assistente social na área da saúde, bem como nos demais espaços em que se insere, sendo chamado cada vez mais a responder às demandas institucionais, em detrimento ao atendimento das necessidades dos sujeitos que demandam sua ação profissional. No que diz respeito aos desafios impostos aos assistentes sociais na área da saúde, Vasconcelos (2011) destaca:

Superar a condição de complementação de serviços médicos, a partir de uma relação secundária não só com a medicina, mas com os demais profissionais de saúde e com os gestores, para, no campo da saúde/doença, sedimentar uma atuação autônoma, mas não isolada e fragmentada das demais profissões, priorizando o enriquecimento da subjetividade, a promoção e a prevenção, sem prejuízo das ações assistenciais (VASCONCELOS, 2011, p. 2).

Essa interpretação crítica do trabalho profissional do assistente social, só é possível, no processo de formação por meio de uma maior aproximação com a realidade que é viabilizada através do estágio supervisionado, de projetos de pesquisa e extensão, visitas técnicas aos espaços institucionais e embasamento teórico e ético-político. Ao estudante 
dever ser viabilizado o conhecimento acerca da Política de Saúde, o cotidiano dos espaços sócio-ocupacionais e os desafios e possibilidades da intervenção profissional do assistente social para a efetivação dos princípios do SUS.

O Curso de Serviço Social da UFTM empreende estratégias para articular as atividades de ensino à pesquisa e à extensão, de forma a considerar as exigências do contexto sócio-cultural-político local e regional, ainda que num contexto de limites institucionais próprio dos rebatimentos da precarização da educação superior na formação profissional em Serviço Social.

Quando perguntados aos estudantes se já haviam participado de alguma atividade de pesquisa, extensão e estágio na área da saúde explicitaram que:

Só [...] no projeto, no início do primeiro período, de comunicação e saúde (MARTE, 2015).

Não, não participei de nenhuma atividade (JUPITER, 2015).

Sim. Eu fiz estágio durante um ano no Hospital de Clínicas da UFTM setor de ambulatório de acolhimento, [...] já fiz dois projetos, um de pesquisa e outro de extensão na área da saúde (SATURNO, 2015).

Sim, participei de atendimento às famílias, orientação acerca dos direitos sociais referentes à saúde da criança, num projeto de extensão. Depois teve o período do estágio com duração de um ano no pronto socorro, no qual atendia os dois públicos tanto adulto quanto criança (PLUTÃO, 2015).

Observamos, contudo que a aproximação com a área da saúde se faz presente nesta formação profissional, seja via estágio, pesquisas, extensão. Por tal, buscamos sistematizar tais espaços formativos articulados com as atividades específicas da Política de Saúde. Assim, abaixo, apenas para fins didáticos da exposição de dados, separamos em tópicos extensão, pesquisa e ensino, mas entendendo que estas são indissociáveis.

\subsection{Extensão}

No que se refere à Extensão Universitária, esta deve ser entendida como um processo educativo, cultural e científico que viabiliza a relação transformadora entre Universidade e sociedade, compreendendo o conjunto de atividades desenvolvidas por estudantes e professores, para a produção e socialização do conhecimento produzido em projetos, cursos, 
eventos, publicações. Tem como fito expandir e apoiar atividades de extensão voltadas à socialização, transformação da sociedade e ao exercício da cidadania, para atender as demandas da mesma. A extensão, portanto, corresponde a uma ação educativa científica interdisciplinar necessária e importante para a formação profissional, pois através dela o estudante estabelece uma ligação entre seus estudos acadêmicos e ações na realidade.

No primeiro ano de implantação do curso de Serviço Social na UFTM foram desenvolvidos nove (09) projetos de extensão, sendo $22 \%$ destes na área de saúde, voltados especificamente para a saúde da criança e do adolescente através da promoção de direitos e a prevenção da violência no ambiente educacional e comunitário, e ações de humanização na UTI neonatal e pediátrica.

Em 2010, com a ampliação do quadro docente do curso, foi possível também a ampliação das ações de extensão, sendo registrados 28 projetos, dos quais 10, ou seja, 36\% foram desenvolvidos na área de saúde.

No ano seguinte (2011), houve 11 projetos desenvolvidos na área da saúde, com ações voltadas para a promoção da saúde para idosos, trabalho com famílias na UTI pediátrica, prática de educação em saúde para pessoas com transtorno mental, além da manutenção dos programas de rádio e a implementação do Programa de Educação pelo Trabalho - PETSaúde Mental.

No ano de 2012 houve uma redução nas atividades de extensão desenvolvidas pelo curso de Serviço Social da UFTM em virtude da participação no movimento grevista das universidades federais que durou cerca de 120 dias. Assim, foram seis (06) projetos de extensão na área da saúde.

No ano de 2014 e no primeiro semestre de 2015 identificamos 6 projetos de extensão na área da saúde, que estão dispostos no quadro a seguir que serviu como coleta de dados com os docentes do Curso de Serviço Social. 
QUADRO 1 - Distribuição dos Projetos de Extensão na Área da Saúde no período de 2013-2015

\begin{tabular}{|c|c|c|c|c|}
\hline Extensão & $\begin{array}{c}\text { Período } \\
\text { de } \\
\text { realização }\end{array}$ & Objetivo geral & $\begin{array}{l}\text { Multidiscip } \\
\text { linar }\end{array}$ & $\begin{array}{c}\text { Estudantes } \\
\text { de Serviço } \\
\text { Social }\end{array}$ \\
\hline $\begin{array}{l}\text { "Comunicação, } \\
\text { educação e } \\
\text { mobilização } \\
\text { social na saúde } \\
\text { em Uberaba- } \\
\text { MG: conhecendo } \\
\text { recursos, } \\
\text { efetivando } \\
\text { direitos" }\end{array}$ & 2013-2014 & $\begin{array}{l}\text { Conhecer a política de } \\
\text { atenção básica em } \\
\text { saúde em Uberaba-MG } \\
\text { fomentando as } \\
\text { perspectivas de } \\
\text { comunicação, educação } \\
\text { popular e mobilização } \\
\text { social. }\end{array}$ & $\mathrm{NÃO}$ & 10 \\
\hline $\begin{array}{l}\text { "Programas de } \\
\text { rádio" }\end{array}$ & 2014 & $\begin{array}{l}\text { Democratizar } \\
\text { informações no âmbito } \\
\text { da política de saúde }\end{array}$ & $\mathrm{NA} \mathrm{AO}$ & 8 \\
\hline $\begin{array}{l}\text { "Oficina } \\
\text { humanização em } \\
\text { saúde" }\end{array}$ & 2014 & $\begin{array}{l}\text { Discutir com } \\
\text { trabalhadores da rede } \\
\text { de saúde a PNH }\end{array}$ & SIM & 8 \\
\hline $\begin{array}{l}\text { "Programas de } \\
\text { vídeo" }\end{array}$ & 2014 & $\begin{array}{l}\text { Elaborar programas de } \\
\text { vídeo relacionados a } \\
\text { saúde com vistas a } \\
\text { fomentar o direito à } \\
\text { saúde }\end{array}$ & SIM & 8 \\
\hline $\begin{array}{l}\text { "Oficina dos } \\
\text { conselheiros" }\end{array}$ & 2014 & $\begin{array}{l}\text { Discutir com os } \\
\text { conselheiros de saúde o } \\
\text { papel do conselho e a } \\
\text { participação social }\end{array}$ & NÃO & 8 \\
\hline $\begin{array}{ll}\text { "Projeto sala } & \text { de } \\
\text { espera } & \text { no } \\
\text { ambulatório } & \text { de } \\
\text { pediatria" } & \end{array}$ & 2015 & $\begin{array}{l}\text { Possibilitar a criação de } \\
\text { espaço humanizado de } \\
\text { assistência à saúde dos } \\
\text { usuários com vistas a } \\
\text { contribuir na qualidade } \\
\text { dos serviços prestados } \\
\text { e para a efetivação do } \\
\text { acesso. }\end{array}$ & NÃO & - \\
\hline
\end{tabular}

FONTE: Elaborado pelos autores (2015).

\subsection{Pesquisa}

Em relação à pesquisa, esta é de suma importância para a formação e para o trabalho profissional do assistente social. O cenário atual, marcado pelo avanço das políticas neoliberais e o desmonte do sistema de proteção social público têm demandado ao Serv. Soc. \& Saúde, Campinas, SP v.16, n. 1 (23), p. 49-80, jan./jun. 2017 E-ISSN 2446-5992 
profissional novas estratégias de intervenção condizentes com o projeto ético-político profissional.

Em tempos de barbárie do capital, no qual todas as esferas da vida são mercantilizadas, se torna necessário o compromisso com a pesquisa na perspectiva críticoreflexiva, na construção de mediações que desvendem as contradições do capital e que tenha a liberdade como valor ético central e as demandas políticas a ela inerentes - autonomia, emancipação e plena expansão dos indivíduos sociais.

Para tanto, a dimensão investigativa deve ser transversal na operacionalização das ações profissionais no sentido de possibilitar leitura e interpretação da realidade que se manifesta na totalidade da vida social, buscando a correlação da particularidade do fenômeno social a intervir com o movimento dialético dessa totalidade concreta com vistas a transformações.

Entendida desse modo, a pesquisa em Serviço Social não é um caminho de neutralidade, mas que exige posicionamento e compromisso com o desvelamento do real, movido e realimentado pelo compromisso ético-político com a classe trabalhadora e suas demandas históricas.

Nos primeiros quatro anos do curso de Serviço Social na UFTM, foram desenvolvidos três projetos de pesquisa na área da saúde, quais sejam: 1. "Dando voz aos sujeitos: perspectivas de atuação do assistente social na área da saúde - PFS (ESF) E NASF- no município de Uberaba-MG."; 2. "Saúde e qualidade de vida do homem: um estudo realizado nas unidades de pronto de atendimento do município de Uberaba-MG"; e, 3. "Exercício profissional do Serviço Social na residência multiprofissional em saúde da UFTM: um estudo com pacientes das clínicas de oncologia, hematologia e endocrinologia” (JULIÃO; BASÍLIO, 2013)

Em relação às pesquisas de conclusão de curso, Julião e Basílio (2013) afirmam que “dos 25 TCCs elaborados pela primeira turma de concluintes do curso de Serviço Social da UFTM, 13 deles estão relacionados à área da saúde, sendo, em sua maioria, decorrentes das experiências de estágio supervisionado realizados pelos estudantes nessa área”.

No ano de 2014 e no primeiro semestre de 2015 identificamos 4 projetos de pesquisa, que estão dispostos no quadro 2 que serviu como coleta de dados com os docentes do curso de Serviço Social. 
Ainda no que tange à pesquisa, é interessante dizer que o projeto político pedagógico do curso de 2010, enfatiza que o curso de Serviço Social da UFTM deva produzir conhecimentos com interfaces à saúde, talvez pela tradição da universidade na produção conhecimentos nessa área do saber. O curso "deverá cumprir o papel de implantar, na Instituição, o desenvolvimento de pesquisas no campo das Ciências Sociais Aplicadas, com interfaces na área de saúde e educação, além de propiciar a integração e a articulação com os demais cursos" (UFTM, 2010, p. 35-36).

Já o projeto político pedagógico do curso de 2014/2015 enfatiza a formação generalista e as diversas áreas de investigação/intervenção do Serviço Social.

É importante dizermos que os 04 estudantes participantes da pesquisas afirmaram que existe em grande medida um direcionamento no que se refere às discussões e práticas na saúde pelo curso de Serviço Social da UFTM.

Em suas falas, os sujeitos relacionam essa particularidade do curso com as determinações universais que a produz, dentre as quais a tradição da universidade na formação de profissionais em saúde, o fato de significativa parte dos docentes terem formação na saúde, além da estrutura física da universidade e da cidade de Uberaba na área da saúde, aspectos que segundo eles contribuem para que a saúde tenha centralidade nas discussões e práticas na saúde, como veremos a seguir.

Eu acredito que o curso de Serviço Social por estar numa universidade que tem tradição na saúde, quase todos os projetos ali dentro da universidade são voltados para a área da saúde. [...] (SATURNO, 2015).

Querendo ou não a gente observa bastante que o curso de Serviço Social aqui da UFTM tem um direcionamento [...], para a área da saúde, devido toda a história da universidade. Por exemplo, os projetos o maior número é na saúde, os estágios também na saúde. Mas depois de ter um amadurecimento maior no decorrer do curso, você acaba tendo uma dimensão das outras áreas também e percebe que são tão importantes quanto e vai aos poucos se identificando (PLUTÃO, 2015). 
QUADRO 2 - Projetos de Pesquisa desenvolvidos e participação de alunos no período de 2013-2015

\begin{tabular}{|c|c|c|c|c|}
\hline Pesquisa & $\begin{array}{l}\text { Período de } \\
\text { realização }\end{array}$ & Objetivo geral & $\begin{array}{l}\text { Multidisci } \\
\text { plinar }\end{array}$ & $\begin{array}{l}\text { Estudantes } \\
\text { de Serviço } \\
\text { Social }\end{array}$ \\
\hline $\begin{array}{l}\text { "A concepção } \\
\text { dos trabalhadores } \\
\text { de porta de } \\
\text { entrada do P.S. } \\
\text { do HC UFTM } \\
\text { acerca da política } \\
\text { de saúde" }\end{array}$ & $\begin{array}{c}2014-1 \mathrm{e} \\
2014-2\end{array}$ & $\begin{array}{l}\text { Conhecer e analisar as } \\
\text { condições de trabalho } \\
\text { de porteiros, agentes } \\
\text { do serviço de porta de } \\
\text { entrada em } \\
\text { consonância à política } \\
\text { de saúde }\end{array}$ & SIM & 02 \\
\hline $\begin{array}{l}\text { "Serviço Social e } \\
\text { Saúde: um olhar } \\
\text { para a formação } \\
\text { profissional" }\end{array}$ & $\begin{array}{c}2014-1 \mathrm{e} \\
2014-2\end{array}$ & $\begin{array}{l}\text { Conhecer o processo } \\
\text { de formação } \\
\text { profissional em } \\
\text { Serviço Social no } \\
\text { curso da UFTM }\end{array}$ & $\mathrm{NÃO}$ & 02 \\
\hline $\begin{array}{l}\text { "O impacto dos } \\
\text { programas de } \\
\text { residência } \\
\text { multiprofissional } \\
\text { implantados em } \\
\text { MG na formação } \\
\text { de especialistas } \\
\text { no SUS" }\end{array}$ & $\begin{array}{c}2014-1 \mathrm{a} \\
2015-1\end{array}$ & $\begin{array}{l}\text { Avaliar o impacto dos } \\
\text { programas de } \\
\text { residência } \\
\text { multiprofissional para } \\
\text { a formação de } \\
\text { especialistas no SUS } \\
\text { em MG }\end{array}$ & SIM & 01 \\
\hline $\begin{array}{l}\text { "Comunicação, } \\
\text { educação } \\
\text { mobilização } \\
\text { social na saúde } \\
\text { em Uberaba- } \\
\text { MG: conhecendo } \\
\text { recursos, } \\
\text { efetivando } \\
\text { direitos"10 }\end{array}$ & 2013-2014 & $\begin{array}{l}\text { Conhecer a política de } \\
\text { saúde e como ela se } \\
\text { processa na cidade de } \\
\text { Uberaba-MG }\end{array}$ & $\mathrm{NÃO}$ & 10 \\
\hline
\end{tabular}

FONTE: Elaborado pelos autores (2015).

$\mathrm{Na}$ mesma perspectiva, os estudantes que não tiveram experiências diretas em extensão, pesquisa ou estágio na saúde disseram:

Acho que existe um direcionamento muito mais na área saúde na UFTM. Primeiro que nós temos o Hospital das Clínicas e segundo que a maioria dos

\footnotetext{
10،Comunicação, educação e mobilização social na saúde em Uberaba-MG: conhecendo recursos, efetivando direitos" trata-se de um projeto de extensão em interface com a pesquisa. O projeto foi composto por 04 etapas.
} 
nossos professores tem formação em saúde e atuam na área da saúde, e acho que isso vai direcionando de certa forma (MARTE, 2015).

O curso na UFTM [...] é mais voltado pra saúde do que pras outras áreas do que o Serviço Social atua, acho que devido à proximidade do hospital escola e por ter maior número de campos de estágio no hospital escola, e também por ter professores que desenvolvem projetos na área da saúde; [...] Essa questão do estágio é muito voltado para a área da saúde. Mas também [...] no decorrer da nossa formação além "da privatização da saúde com a implantação da EBSERH (são temas da saúde que foram muito abordados), tem-se também a questão de movimentos sociais, reforma agrária que são temas muito fortes aqui na nossa região e que está começando a ser discutido" (JUPITER, 2015).

\subsection{Ensino}

No que tange à dimensão ensino foram analisadas as disciplinas que compõem a grade curricular do curso, envolvendo as suas matrizes curriculares de 2010 e de $2014^{11}$, e o estágio supervisionado - relativo aos dois semestres de 2014, tendo com parâmetro os campos de estágio e a quantidade de estagiários. Além disso, a entrevista semiestruturada com os estudantes nos permitiu, apanhar o conhecimento que os mesmos possuem acerca da política de saúde e a atuação do assistente social nessa área na atual conjuntura.

No que se refere às disciplinas da matriz curricular de 2010 encontramos as seguintes que se relacionam com as discussões da área da saúde: Política Social e Serviço Social I, II e III; Legislação Social aplicada ao Serviço Social I; e, Planejamento e Gestão de Politicas Sociais I e II.

Quanto às disciplinas da matriz curricular de 2014 temos: Política Social e Serviço Social I; Política Social e Serviço Social II; Política Social e Serviço Social III; Legislação aplicada ao Serviço Social II; Planejamento e Gestão de Politicas Sociais I; Planejamento e Gestão de Politicas Sociais II; além da disciplina eletiva Saúde e Serviço Social.

\footnotetext{
${ }^{11}$ É importante ressaltar que o Projeto pedagógico do curso passou por um processo de revisão no ano de 2014, mediante a necessidade de aprimorar algumas disciplinas e discussões. Nesse sentido foram analisados os projetos pedagógicos de 2010 e 2014.
} 
Quando perguntado sobre como o tema saúde é trabalhado na formação profissional, no que se referem às disciplinas, unidades temáticas, e atividades teóricas e práticas, os estudantes que participaram de atividades na saúde responderam que:

Acho que falta muita coisa ainda [...], por exemplo, política de humanização e entender essa política no cotidiano (SATURNO, 2015).

Ah, discussão sempre é bom ter mais! Acredito que é o suficiente e o bastante. [...] (PLUTÃO, 2015).

Já os estudantes que não tiveram participação em atividades na área da saúde responderam que:

A política de saúde acho que foi abordada em algumas disciplinas como gestão social, mas principalmente em trabalhos e seminários que alguns grupos ficavam com a temática. [...] O que a gente mais vê de área temática acho que foi na área da saúde de modo geral, e acho que o jeito que ela foi tratada por algumas disciplinas muito bem tratadas (MARTE, 2015).

Não se tem uma disciplina especifica voltada pra saúde, ela é colocada em disciplina diversas que as vezes está se tratando de uma temática mas que pode se lucidar com exemplo da saúde, por exemplo, devido a proximidade que o curso tem com a saúde. [...] Aqui, traz-se muito a saúde no decorrer da formação profissional, do curso de Serviço Social na UFTM, tem muitos projetos envolvidos na área da saúde a maioria dos nossos projetos acho que as professoras desenvolvem são na área da saúde. A própria pós-graduação, especialização, a residência multiprofissional é voltada para a saúde. Apesar de não ter uma disciplina "saúde e Serviço Social", por exemplo, essa temática está sempre ali presente [...] (JUPITER, 2015).

Em suas falas os sujeitos entrevistados deixam em evidência questões como a relação entre teoria e prática no Serviço Social, a confusão entre uma formação generalista e uma formação superficial; além de explicitarem a discussão de algumas temáticas contemporâneas acerca da política de saúde como a questão da humanização na saúde e dos modelos privatizantes de gestão como a Empresa Brasileira de Serviços Hospitalares (EBSERH).

Os estudantes relataram a disciplina de "gestão" como uma das que discutiam a temática da saúde, mas percebemos na análise do Projeto Pedagógico que o tema saúde é transversal, e que, as disciplinas de "Política Social e Serviço Social I, II e III", em ambas as matrizes curriculares, discutem a natureza e função das políticas sociais no Estado capitalista, o conceito e particularidades do Welfare State, o sistema de proteção social brasileiro e suas particularidades, os dilemas e contradições na configuração das políticas sociais no estado 
neoliberal, a questão da seletividade e da focalização das políticas sociais, e a saúde enquanto política social nesse contexto.

As disciplinas de "Legislação aplicada ao Serviço Social I e II", em ambos os projetos pedagógicos discutem a organização política do Estado e administração pública, os direitos humanos e sociais, a Constituição Federal de 1988, além das legislações que regulamentam a política de saúde no Brasil, no conjunto das outras legislações sociais.

Com o intuito de vislumbrar o que os estudantes apreenderam sobre essas legislações no decorrer de sua formação na UFTM, perguntamos o que eles conheciam das Leis n. 8080 e n. 8142 de 1990. De acordo com os estudantes entrevistados:

[...] com a instituição dessas leis muda muito. Primeiro por ser um serviço público e universal, para todo mundo acessar, e uma participação social eu acho com um maior controle da sociedade, perante aos serviços. Porém acredito que não é tão efetivo, por conta de interesses, das correlações de forças [...] (MARTE, 2015).

Com o SUS a saúde é considerada direito de todos e dever do Estado, então essa foi uma mudança muito significativa (PLUTÃO, 2015).

Antes dessa lei n. 8.080 de 1990 a saúde não era vista como acesso universal, era voltada para previdenciária, bem antes, agora você vê que a saúde, no marco constitucional com a instituição do sistema único de saúde todos passam a ter acesso a saúde, ela é universal, sem distinção. Tem ainda essa questão de participação popular, já que tem os conselhos, as conferências (SATURNO, 2015).

Eu acho que a partir delas tem-se uma maior transparência nos processos licitatórios mesmo, da gestão dos próprios hospitais. Eu acho que melhora no acesso as informações que muitas vezes são centralizados nas mãos dos gestores. Acho também que tem que se pensar como vai se dar essa participação, por que muitas vezes os conselhos trazem palavras, expressões, que não são acessíveis assim a nível do conhecimento da população, questões muitos burocráticas assim e que a população não consegue compreender o que está sendo discutido, então eu acho que para isso funcionar tem que ser um nível de discussão bem acessível mesmo, a palavra é acessível pra população compreender aprender e poder participar de fato não só ter uma participação fictícia (JUPITER, 2015).

Percebemos por meio das falas acima que os estudantes compreendem que com a instituição das legislações sociais no marco da Constituição Federal, como o Sistema Único de Saúde significou um avanço especificamente no que tange o reconhecimento da saúde como direito social e componente de cidadania numa perspectiva democrática e participativa. Pelas falas também fica evidente que esta proposta de saúde tem sido fragilizada num processo de desmonte dos direitos sociais e contrarreforma do Estado.

Serv. Soc. \& Saúde, Campinas, SP v.16, n. 1 (23), p. 49-80, jan./jun. 2017 E-ISSN 2446-5992 
As disciplinas de "Planejamento e Gestão de Politicas Sociais I e II" discutem os fundamentos do planejamento e da gestão pública brasileira, a contrarreforma do Estado brasileiro e as novas relações entre Estado e Sociedade, as tendências da gestão de políticas sociais no capitalismo contemporâneo, a dimensão do planejamento e da gestão das políticas sociais para o trabalho profissional do assistente social, a descentralização, participação e controle social no planejamento e gestão das políticas sociais, o financiamento na constituição das políticas sociais e a política de saúde nesse contexto.

Assim, como visto em ambos os projetos pedagógicos, a saúde não é discutida de modo deslocado das demais políticas sociais que compõem a Seguridade Social Brasileira, o que expressa à característica da formação generalista em Serviço Social.

A partir desses dados podemos observar que no que tange às disciplinas da matriz curricular de 2014, a saúde não possui centralidade nas discussões que perpassam pelo processo de formação em Serviço Social na UFTM, coerente com a proposta da formação generalista, preconizada nas Diretrizes Curriculares da ABEPSS.

Entretanto é preciso salientar que para se compreender o trabalho do assistente social na Política de Saúde, apenas as discussões que dizem respeito à política de saúde não basta, as disciplinas de "Fundamentos teórico-metodológicos e ético políticos do Serviço Social I, II, III e IV" bem como "Serviço Social e Processo de Trabalho I e II", são fundamentais para que se vislumbre as possibilidades de trabalho do assistente social nos diversos campos de atuação, inclusive para compreender a inserção da profissão na divisão social e técnica do trabalho e abarcar suas especificidades.

Quando perguntados sobre como as experiências nas atividades de pesquisa, extensão ou estágio na saúde contribuíram para a formação profissional, responderam que:

As experiências foram um pouco imaturas porque eu estava bem no começo do curso então eu não tinha maturidade o suficiente para aproveitar e entender a importância dessas atividades para o assistente social na saúde, como em outras áreas também, assistência e previdência. Mas hoje em dia eu vejo isso, que eu poderia ter aproveitado um pouco mais, mas, enfim, era o momento, por imaturidade mesmo que eu não aproveitei tanto. No meu estágio a gente atendia as demandas mais imediatas mesmo, porque o pronto socorro o que acontece, chega de tudo lá, a todo momento, você tem que estar dando respostas, você tem que estudar, tem que perguntar porque lá é tudo muito rápido, muito passageiro (PLUTÃO, 2015).

Tanto o estágio, quanto os projetos de extensão e pesquisa possibilitam uma aproximação com a realidade, por que não fica só aquela coisa vista em sala

Serv. Soc. \& Saúde, Campinas, SP v.16, n. 1 (23), p. 49-80, jan./jun. 2017 E-ISSN 2446-5992 
de aula. Você tem contato com a realidade. O projeto de extensão proporciona você participar diretamente com a comunidade, porque traz essa questão da Universidade pública, que é voltada para comunidade além de contribuir muito com a formação profissional. É através desses espaços que você conhece quais as políticas de saúde, e é nesses espaços que possibilita você a ter uma maior aproximação e uma materialização da política de saúde. Como ela se materializa no cotidiano (SATURNO, 2015).

No que se refere ao estágio supervisionado em Serviço Social, este é uma importante atividade da formação profissional, pois possibilita o contato do estudante com a realidade concreta, podendo desenvolver habilidades e competências com vistas à transformação do cotidiano conservador. O processo dialógico de ensino-aprendizagem entre estagiário e supervisores acadêmicos e de campo, permite desenvolver competências a partir dos fenômenos sociais concretos que demandam ao profissional estratégias de intervenção, tendo em vista a articulação teoria e prática.

O estágio é entendido como um processo que perpassa dialeticamente pela realidade cotidiana da formação e do exercício profissional, entendido como uma mediação entre teoria e prática que, num processo de ensino-aprendizagem, estabelece uma relação direta com a realidade social.

Nessa perspectiva, as Diretrizes Curriculares para o Curso de Serviço Social, destacam o estágio supervisionado como uma das atividades obrigatória e integradora do currículo a partir da inserção do estudante no espaço sócio institucional objetivando capacitálo para o exercício do trabalho profissional.

Barbosa (2004) nos afirma que o estágio é uma

[...] interação teoria-prática, mais do que aprendizagem, compreende uma vivência, não podendo ser reduzido a um treinamento para aprender o "como fazer" sem que o entendimento acompanhe o "por que" e o "para quê" da ação. Daí entendermos que, no estágio, o estudante vivencia a práxis profissional e ao vivenciá-la aprende a utilizar o instrumental e a interagir numa rede institucional e pessoal, em situações concretas e desafiadoras (BARBOSA, 2004).

No que se refere ao estágio supervisionado, os dados obtidos no primeiro semestre de 2014 no curso de Serviço Social da UFTM explicitam que dos 34 campos de estágio, 09 eram campos na área da saúde, ou seja, uma porcentagem de $26 \%$. No que se refere à quantidade de estudantes, fica o destaque para a área da política de saúde. No primeiro semestre de 2014, 
dos 82 estagiários $^{12}, 42$ estavam atuando na área da saúde, ou seja, 51\%. A área da saúde concentrou mais da metade da somatória dos estagiários de todas as outras áreas juntas.

Percebemos ainda que os estagiários estavam inseridos por toda a Rede de Atenção à Saúde no município de Uberaba, seja na atenção básica (NASF - Núcleo de Apoio a Saúde da Família) seja na atenção secundária (CAISM - Centro de Atenção Integral à Saúde da Mulher, CEREST - Centro de Referência em Saúde do Trabalhador, Instituto de Hemodiálise e Transplante Renal de Uberaba, Sanatório Espírita de Uberaba, Unidade de Pronto Atendimento, seja na atenção de alta complexidade, em hospitais da cidade, o que está em consonância com o princípio de integralidade do SUS.

Dos 38 campos de estágio no segundo semestre de 2014, 36\% eram campos na área da saúde. No que se refere à quantidade de estudantes, dos 92 estagiários do segundo semestre de 2014, 42 eram da na área da saúde, uma porcentagem de $46 \%$.

Traçando um comparativo entre o primeiro e o segundo semestre de 2014, percebemos que a quantidade de campos de estágio na área da saúde passou de 09 para 14, considerando a ampliação de contratação também de assistentes sociais nos espaços como Centro de Reabilitação da UFTM; na Saúde privada como Unimed - Sociedade Cooperativa de Trabalho Médico; nos Núcleos de Atendimento a Saúde da Família, no projeto municipal Consultório de Rua; nas Unidades Básicas de Saúde, o que denota a expansão no mercado de trabalho para o assistente social, nestes tempos desastrosos de lutas pela efetivação dos direitos sociais arduamente construídos e constituídos em legislação suprema que é a Constituição Federal de 1988.

\section{CONSIDERAÇÕES FINAIS}

O estudo nos permitiu conhecer as atividades de ensino, pesquisa e extensão que vem sendo desenvolvidas na formação profissional em Serviço Social no âmbito da área da política de saúde. As atividades contemplam importante espaço de formação profissional, por viabilizarem uma aproximação com as possibilidades e desafios profissionais na área da saúde, bem como uma apreensão crítica da práxis profissional nessa área de atuação.

\footnotetext{
${ }^{12}$ (Estudantes dos $5^{\circ}, 6^{\circ}, 7^{\circ}$ e $8^{\circ}$ períodos, matriculados na disciplina de supervisão de estágio).
} 
Seguindo a trajetória histórica da UFTM, as pesquisas científicas, as atividades de extensão e estágio do curso de Serviço Social estão voltadas principalmente para a área da saúde. O Hospital de Clínicas, além de um importante espaço para a realização de estágio curricular dos estudantes, constitui também como um campo para a pesquisa científica e a extensão.

Apesar do destaque que área da saúde possui nas atividades de ensino, pesquisa e extensão do curso, percebemos que não interfere na garantia da formação generalista em Serviço Social. Por outro lado, a posição de destaque que a saúde possui se deve à condição histórica da universidade na formação de profissionais para atuarem na saúde bem como na produção de conhecimentos no campo da saúde pública. Ao nosso olhar, a ênfase no campo da saúde, se refere a uma questão objetiva que advém do protagonismo da cidade e da universidade na formação de recursos humanos na área da saúde, o que acompanhando a dinâmica da realidade histórica tem-se alcançado horizontes mais amplos da vida social.

Por fim, é importante dizermos que o Projeto Político Pedagógico de curso deve ser dinâmico e acompanhar o debate hegemônico da categoria profissional. Nesse sentido, a atualização do PPPC (2014) se constituiu como expressão do movimento dialético para garantir uma formação profissional mais generalista, que caminha na direção da formação profissional condizente com o projeto ético e político.

Recebido em 12.03.2016 - Aprovado em 28.06.2017

\section{REFERÊNCIAS}

ABEPSS. Diretrizes Curriculares para o Curso de Serviço Social. Brasília, 1996.

BARBOSA, A. M. G. O importante papel do estágio no desenvolvimento de competências.

Revista Ágora - Fascículo Atual. Ano I. No. 01. Outubro de 2004.

BRASIL. Constituição Federal da República Federativa do Brasil, Brasília, 1988.

BRASIL. Ministério da Saúde. Lei Orgânica da Saúde. Lei n. 8.080/90 e Lei 8.142/90.

Diário Oficial da União, Brasília 1996.

BRAVO, M. I. S. Serviço Social e Reforma Sanitária: lutas sociais e práticas profissionais - 2ed. - São Paulo, Cortez, 2007 
CFESS. Parâmetros para atuação de assistentes sociais na política de saúde. Trabalho e projeto profissional nas políticas sociais. Brasília, 2010.

CFESS. Código de Ética do Assistente Social. 1993.

IAMAMOTO, M. V. O Serviço Social na cena contemporânea. In: CFESS/ABEPSS.

Serviço Social: direitos e competências. Brasília: CFESS/ABEPSS, 2009.

IAMAMOTO, M. V. O Serviço Social na contemporaneidade: trabalho e formação profissional. - 23.ed. - São Paulo: Cortez, 2012.

IAMAMOTO, M. V. Serviço Social em tempo de capital fetiche: capital financeiro, trabalho, e questão social. São Paulo: Cortez, 2010.

JULIÃO, C. H.; BASÍLIO, D. S. Formação Profissional do Assistente Social na UFTM: a saúde nas atividades de pesquisa e extensão. In: V Fórum Sócio-jurídico: Direito à Saúde e à Dignidade Humana, 2013, Franca, p. 502-511.

KOSIK, K. Dialética do concreto. Rio de Janeiro: Paz e Terra, 1969.

MARX, K. Contribuição à crítica da economia política. São Paulo: Martins Fontes, 1983. MARX, K. Crítica ao programa de Gotha. In: ANTUNES, R. A dialética do trabalho. São Paulo: Expressão popular, 2013.

MARX, K.; ENGELS, F. A ideologia alemã. São Paulo: Expressão Popular, 2009.

MARX, K.; ENGELS, F. Obras escolhidas em três volumes. Rio de Janeiro: Vitória, 1963. MINAYO, M. C. de S. O desafio do conhecimento: pesquisa qualitativa em saúde. - 13. ed. - São Paulo: HUCITEC, 2013

MOTA, A. E. et al. Serviço Social e Saúde: formação e trabalho profissional. São Paulo: Cortez, 2009.

NETTO, J. P. Crise do capital e consequências societárias. Serviço Social e Sociedade. São Paulo, n. 111, p. 413-429, jul./set. 2012.

NETTO, J. P. Ditadura e Serviço Social no Brasil pós-64. São Paulo: Cortez, 2009.

NETTO, J. P. Introdução ao estudo do método em Marx. São Paulo: Boitempo, 2011.

NETTO, J. P.; BRAZ, M. Economia Política: uma introdução crítica. São Paulo: Cortez, 2006.

SILVA, M. O. S. e. O Serviço Social e o popular: resgate teórico-metodológico do projeto profissional de ruptura. 6. ed. São Paulo: Cortez, 1995.

TEIXEIRA, F. J. S. O neoliberalismo em debate. In: TEIXEIRA, F. J. S.; OLIVEIRA, M. A. de (Orgs.). Neoliberalismo e reestruturação produtiva: as novas determinações do mundo do trabalho. São Paulo: Cortez; Fortaleza: Universidade Estadual do Ceará, 1996, p. 195-252. Serv. Soc. \& Saúde, Campinas, SP v.16, n. 1 (23), p. 49-80, jan./jun. 2017 E-ISSN 2446-5992 
VASCONCElOS, A. M. A Prática do Serviço Social: Cotidiano, Formação e Alternativas na Área da Saúde - 8ª . Ed., 2011. 